\title{
Fuzzy Logic in Traffic Engineering: A Review on Signal Control
}

\author{
Milan Koukol, ${ }^{1}$ Lenka Zajíčková, ${ }^{2}$ Lukáš Marek, ${ }^{2}$ and Pavel Tuček ${ }^{2}$ \\ ${ }^{1}$ Department of Applied Informatics in Transportation, Faculty of Transportation Sciences, Czech Technical University, \\ Konviktská 20, 11000 Praha 1, Czech Republic \\ ${ }^{2}$ Department of Geoinformatics, Faculty of Science, Palacký University Olomouc, 17. Listopadu 50, 77146 Olomouc, Czech Republic
}

Correspondence should be addressed to Pavel Tuček; pavel.tucek@upol.cz

Received 1 August 2014; Accepted 17 December 2014

Academic Editor: Feng Wang

Copyright (C) 2015 Milan Koukol et al. This is an open access article distributed under the Creative Commons Attribution License, which permits unrestricted use, distribution, and reproduction in any medium, provided the original work is properly cited.

Since 1965 when the fuzzy logic and fuzzy algebra were introduced by Lotfi Zadeh, the fuzzy theory successfully found its applications in the wide range of subject fields. This is mainly due to its ability to process various data, including vague or uncertain data, and provide results that are suitable for the decision making. This paper aims to provide comprehensive overview of literature on fuzzy control systems used for the management of the road traffic flow at road junctions. Several theoretical approaches from basic fuzzy models from the late 1970s to most recent combinations of real-time data with fuzzy inference system and genetic algorithms are mentioned and discussed throughout the paper. In most cases, fuzzy logic controllers provide considerable improvements in the efficiency of traffic junctions' management.

\section{Introduction}

The condensed traffic together with the increasing number of cars requires constantly evolving and more complex solution of traffic situation including the traffic signal control. The monitoring and controlling of traffic within the city became a crucial task because of the ability to take control of roads and thus directly impact on the quality of life. Nowadays, the traffic signal controllers use almost real-time data and combine them with sophisticated algorithms. These algorithms used at first simple mathematic rules that were suitable for the purpose of lower load of intersections but started to be outdated with the development of dense road network and increasing number of vehicles. Current algorithms have to be more adaptive and intelligent in order to handle everchanging traffic situations. It means that the decision support systems should be able to implement and handle almost reallife rules which are very similar to the human thinking.

These conditions are fulfilled by the implementation of fuzzy logic processes and fuzzy logic algebra into the controlling scheme. For example, humans would think in the following way to control traffic situation at a certain junction: "if the traffic is heavier on the north or south lanes and the traffic on the west or east lanes is less, then the traffic lights should stay green longer for the north and south lanes." Such rules can now be easily accommodated in the fuzzy logic controller. The main strength of the fuzzy logic is that it allows fuzzy terms and conditions such as "heavy," "less," and "longer" to be quantized and understood by the computer [1]

Fuzzy numbers are special cases of fuzzy sets that represent vague, imprecise, or ill-known values. Like the fuzzy set a fuzzy number is defined by a membership function, which specifies membership degree for each element $x$ from the universe $X$. The membership function of fuzzy number $\widetilde{A}$ is usually denoted as $\mu_{\widetilde{A}}(x)$. Fuzzy number must be a normal convex fuzzy set, with at least piecewise continuous membership function that is defined on the universe of real numbers $[2,3]$. Fuzzy numbers are proven to be well suited for calculation with imprecise values in situation when uncertainty of the value is not result of variability $[2,3]$. Fuzzy number then forms bounds around uncertain value and allows further processing of such vague value by means of fuzzy arithmetic.

Since 1965 when the fuzzy logic and fuzzy algebra were introduced by Lotfi Zadeh, the fuzzy theory successfully found its applications in the wide range of subject fields. The traffic signal control and the management of roads and junctions within the city are no exceptions. The first attempt of applying fuzzy logic in the light signalling equipment using fuzzy logic controller was realized in the late 1970s by Pappis and Mamdani. However, since then, the evolution of fuzzy 
logic controlling systems came to the more complex, more adaptive, and more intelligent frameworks that allow not only the use of fuzzy logic but also combination with real time data and optimization using, for example, genetic algorithms and neural networks.

There have been several standard studies $[4,5]$ focusing on various approaches of modelling and predicting the behaviour of traffic. On one hand, deterministic models are exploited to describe the real situation. The advantage of this methodology lies in its stability and easy tackling. On the other hand, they suffer from inability to react promptly to unexpected changes in driver's behaviour. In this respect, the fuzzy theory offers potential to work both with the significant changes that rapidly affect the continuity of the traffic and also with the small changes that can be hard to be handled statistically; however their impact might be of crucial importance. In the course of development, many stochastic approaches have been introduced [6]; however the combination with the fuzzy logic still exhibits the best reliability.

For the purpose of this paper, we selected and reviewed a solid series of papers reported in the literature. In order to provide a comprehensive overview of the topic, we employed the most popular and recognized databases of scientific paper (e.g. ScienceDirect, Web of Science, or Scopus). Nevertheless the main scope of this paper is not only to present possible ways of evolution and implementation of fuzzy logic in the traffic management but also to refer to the chronology of the evolution and to common relations among presented models. Individual models presented in this contribution are significantly described and usually depicted in the form of simple scheme, so the reader can easily compare them. In most cases, fuzzy logic controllers (and their adjustments and variations) provide considerable improvements in the efficiency of traffic junctions' management compared to the traditional adaptive and nonfuzzy systems.

The organization of this paper is quite simple and straightforward and is given as follows. After the introduction of the topic in Section 1, we chronologically describe the progress in application of fuzzy logic in traffic control in Section 2, where models are described (textually and graphically) and evaluated. Section 3 then concludes all findings.

\section{Progress of Fuzzy Logic in Traffic Control}

Fuzzy logic in the LSE (light signalling equipment) was presented for the first time in 1977 by Pappis and Mamdani [7]. In their paper they described a theoretical model of application of the fuzzy logic controller (FLC) on isolated intersections of two one-way streets with LSE. The system was supplied with the number of approaching vehicles, the length of the column at a time, while the authors used for fuzzification the multidimensional Mamdani implication [8]. In comparison with the conventional dynamic control the FLC achieved a decrease of time delay of the vehicles by $10-21 \%$. In the 1980 s Nakatsuyama et al. [9] used fuzzy logic for the coordination of two successive one-way direct intersections.
The goal was to determine the offset parameter, that is, to determine the time difference between the start of the green phase on the first and the second intersection.

The publication by Bisset and Kelsey [10], which focused on comparison of the conventional adaptive control and the LSE fuzzy control for isolated intersection using graphical simulation ( $X$ window system), represented a significant progress in using fuzzy logic for the intersection control. It was one of the first graphical microscopic simulations as they are being understood today. Along with driving through the rectangular intersection it was possible to turn left or right, while it was possible to modify the geometry in the sense of the number of lanes. However the description of the geometry did not include the determination of the curves' diameters. The simulation also allowed the modification of the intensity of vehicles and the detectors' location (every lane contained two detectors). The control system received values of intensity and cycle length, use of $\Lambda, \Pi$ function. The output was the degree of necessary change of signal on LTE. The tested fuzzy control system showed, in comparison with adaptive control, higher efficiency (permeability) close to the saturation point. In the next article Kelsey et al. [11] included in the variables also the density of traffic on the road, discrimination of open and closed directions of the route, elapsed time from the last phase change, and the necessary degree of control on the isolated intersection.

The 1993 publication [12] by Favilla et al. described the use of the fuzzy traffic control system "(FTC) fuzzy traffic controller," which contained dedicated fuzzy control system FLC (for the setting of the green-light duration according to the traffic conditions), "state machine" (for control of FTC status sequence), and the so-called adaptive module (by changing the FLC setting it is possible to improve "the performance" of the control system); see Figure 1.

The control system was applied on a real independent multilane intersection in the city of São Paulo. The inputs into the control system did not change, and still there were the number of passing vehicles and the column length, whereas the output was again the extension of the green light $(s)$ for the appropriate phase using the $\Lambda$ function. The comparison with the "Mamdani" [7] fuzzy control system proved the contribution of the fuzzy control system containing the socalled adaptive module in the form of the decrease of the average vehicle delay.

Hoyer and Jumar [37] designed a control system which processed traffic information from each lane in the intersection. They used 12 main flows (approaches) of the intersection and the fuzzy rules decided to use on two-, three-, or fourphase signal plan so that the individual traffic lanes were not in conflict.

Kim's thesis [38], dealing with the development of a dynamic control system for LSE with the application of fuzzy logic and Petri nets (discrete distributed system), meant a significant progress in the field of combination of mathematically different control systems for one LSE. The intersection in question contained individual lanes for left and right turns and control algorithm extended the duration of the green phase based on evaluation of data at the end of each phase. 


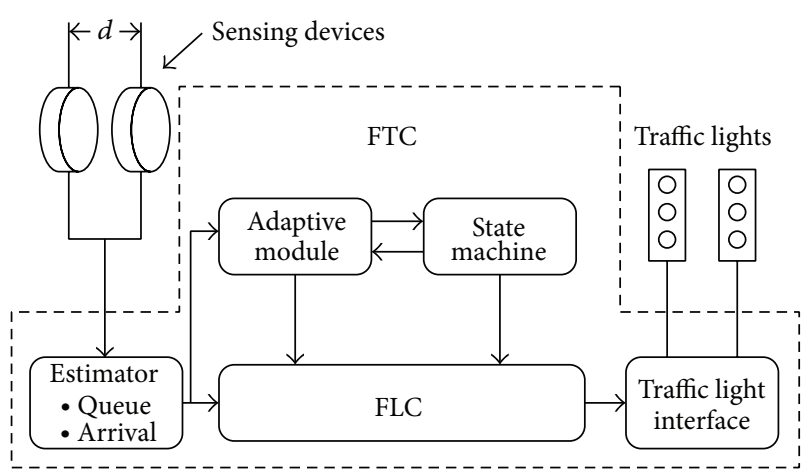

FIGURE 1: Block diagram of the fuzzy traffic control system [12].

Sayers et al. [39] dealt with the description of insufficiencies of traffic-dependent control at an isolated intersection, when the input is nonlinear characteristic, and with removing the insufficiencies using the fuzzy control system.

The 1995 paper by Kagolanu et al. [13] represented one of the first articles, combining the fuzzy logic and Neural networks. The traffic data (intensity, delay, and phase diagram) was the input of the three-layer Neural network and the optimal function of fitness (the Neural diagram, see Figure 2) was the traffic data (intensity, delay, and phase diagram) and the output was the optimal function of fitness (the Neural network diagram, see Figure 2).

Tan et al. [1] resumed the ideas of the article [10] when they created a graphical interface in visual basic for testing of LSE control systems and for support of the implementation of fuzzy into the LSE control system (see Figure 3). It was simple microsimulation software for testing and comparison of fuzzy control and fixed signals plan. The software allowed flexible testing of different variants of vehicle routing and loading of the intersection. According to the results, the LSE fuzzy control system is more efficient than the current control systems from the perspective of the density of the traffic flow, waiting time, time of the vehicle movement, and costs. The costs (the so-called "cost function") have been calculated based on the formula:

$$
\text { Price }=\left(\frac{\text { Vehicles In }}{\text { Vehicles Out }}\right) *\left(\frac{\text { Waiting time }}{\text { Driving time }}\right) \text {. }
$$

Figure 3 is the authors' presentation of the proposal for placement of detectors within the intersection together with definition of the input variables, vehicle approach and column length (the $\Lambda$ functions were used in the fuzzy system).

In his article Kim [40] presented FLC fuzzy control system for adaptive traffic control and came to a conclusion that the proposed solution reacted to the approach of vehicles and length of columns with sufficient flexibility. It also resulted in the enunciation that the proposed fuzzy control system excelled the conventional control system as well as the Mamdani fuzzy regulator [8] not only in terms of intersection permeability but also in terms of the average delay of vehicles and the saturation degree.

An attempt to innovate the issue of LSE fuzzy control came from Beauchamp-Baez et al. [14] in the form of utilization of fuzzy for selection of the intersection phases and

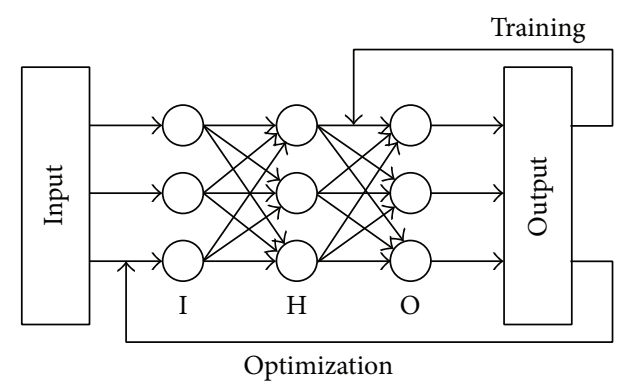

FIgURE 2: Neural network diagram [13].

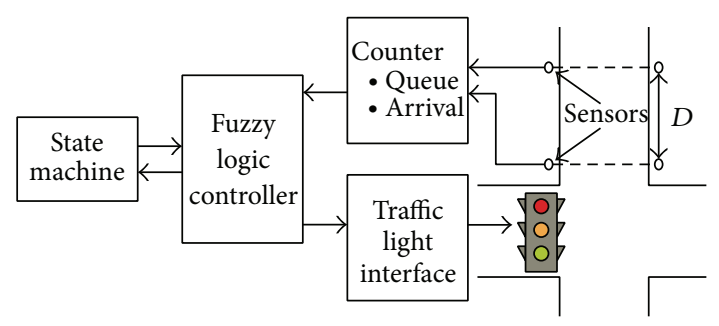

FIgURE 3: Diagram of detectors' placement [1].

for determination of when to change the phase. Firstly, the authors [14] proposed the "traditional" fuzzy control system using the $\Lambda$, $\Pi$ function for isolated intersection, (called FLCTS-Fuzzy Logic Controller for Traffic Systems), see block diagram Figure 4.

And subsequently they included a module for phase "sequencer" (PS), which also used the fuzzy logic (block diagram Figure 5).

The quality of the two above mentioned control systems ("FLC-TS", "PS + FLC-TS") undisputedly exceeded the current LSE control with fixed signal plan; however, more pronounced differences in control quality between "FLC-TS" and "PS + FLC-TS" were not proven.

The Finn Niittymaki came with a new idea of using the fuzzy logic for the SLE control, when he, in his article [41], published for the first time the role of optimization of the decision-making process for the control of the pedestrian crossing using the LSE. Together with Kikuchi they strived to design a fuzzy system to find a compromise between the minimizing of time losses of the pedestrians and vehicles. A team at the Helsinki University developed a microsimulation software HUTSIM (Helsinki University of Technology Simulator) for modelling and evaluation, as an elaboration of the publication [10] and the article [40]. As in all the preceding articles the conclusion consisted of the statement that the fuzzy control system provides a better solution than the conventional traffic-dependent control.

The authors Heung and Ho [15] proposed for the first time a hierarchic control system containing fuzzy logic and a genetic algorithm (GA, genetic algorithm based on off-line learning algorithm) used for generation of fuzzy rules. In the hierarchic control system using GA the number of used rules decreased as well as the "complexity" of the entire system. The proposed system also showed better (lower) values of the 


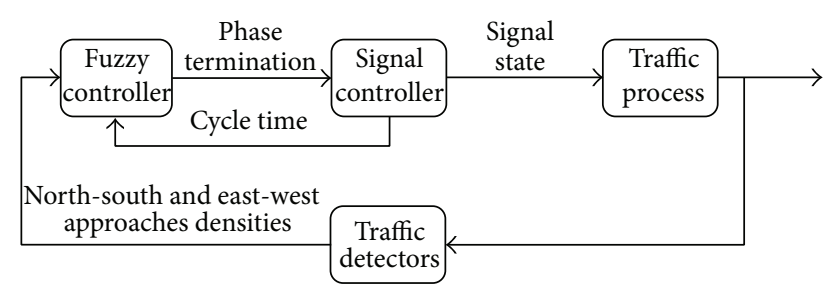

FIGURE 4: Block diagram of the isolated intersection control system “FLC-TS" [14].

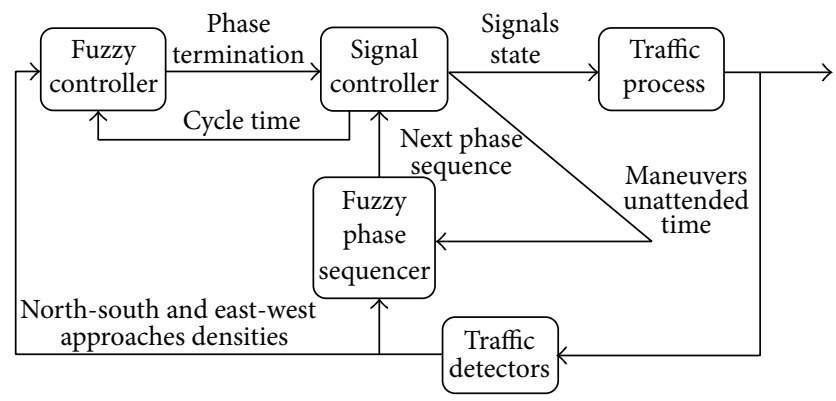

FIGURE 5: Block diagram of the isolated intersection control system “PS + FLC-TS" [14].

average time delay of vehicles than the fixed signal plan (block diagram see Figure 6).

Sayers et al. [42] described the design of the flexible fuzzy control system, which can be applied to a selected task (as needed) based on the selection of several criteria. In the publication [42] the authors also described the sensitivity of the control upon a change of parameters. The authors also followed the idea presented in the article [15] and used the multicriteria optimization genetic algorithm ((MOGA) multiobjective genetic algorithm) as the optimization technique for the deduction of the optimal solution for a fuzzy control system.

Trabia et al. [43] designed an adaptive control system with application of a "two-stage" fuzzy logic. For an isolated intersection with a dedicated lane for left-turns they created a "classical" adaptive system, which modified the signal plan based on information on the traffic flow. On the first stage of the two-stage fuzzy logic the system estimated the intensity of the traffic flow on each approach and on the second stage the system determined the extension or termination of the current phase. This fuzzy control system, in which the functions $\Lambda$, $\Pi$ were used, shows improvement of the average vehicle delay by $9.5 \%$ compared to the traffic-dependent control.

The issue of a multiphase control was also elaborated by the Finn Niittymäki in the publication [44] in which Niittymäki and his colleague Pursula continued in the publication [16] where they described the development of the FUSICO (fuzzy signal control) control algorithm. The FUSICO system (see Figure 7) was a practical application of the described three-phase control in the publication [44]. During the first phase the evaluation of the intensity and occupancy of the detector was used for decision of the degree of the intersection loading (zero, normal, and high); in the second phase the decision of the phase selection and its

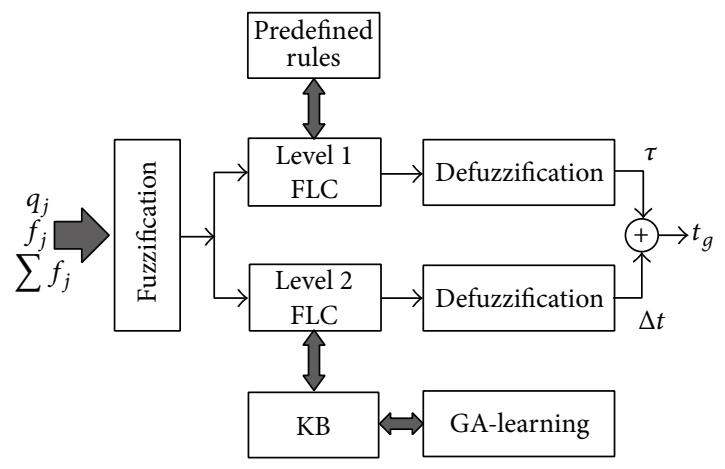

Figure 6: Control block diagram [15].

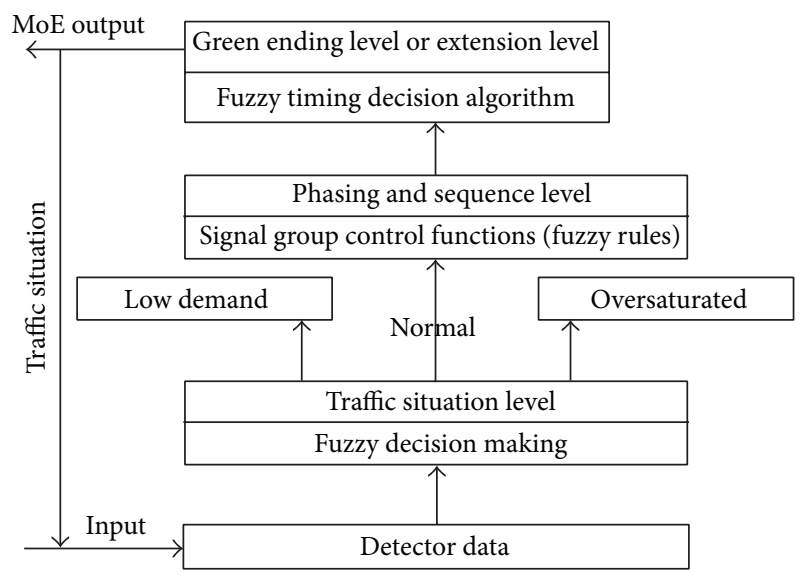

FIGURE 7: Block diagram of the FUSICO three-stage algorithm [16].

sequence was made and the last phase determined the termination or extension of the "go" signal of the selected phase. The authors also specified three main reasons for the introduction of the fuzzy logic into the LSE control systems; these are the increase of the traffic safety, minimizing the time delay of vehicles and minimizing of the environmental impact.

The proposed control system showed, upon comparison with conventional methods of LSE control and fuzzy control system "Pappis Mamdani" [7], distinct improvement of traffic quality. Upon a more detailed inspection the authors came to the conclusion that the system showed decrease in the time delay of vehicles compared to the conventional methods ("Vehicle Actuated"); however, the decrease in vehicle stops occurred only in the area of low intensities (150 to $500 \mathrm{veh} / \mathrm{h}$ ). Niittymäki further worked on the definition of the fuzzy rules for the FUSICO multistage algorithm (i.e., fuzzy rules for phase selection, its sequence, and length) in the followup publication [45]. However, Niittymäki used the FUSICO algorithm also for control of the mutual coordination of two subsequent intersections with LSE [46] and thus followed upon the publication [9]. The model's results showed that it was more appropriate to use the FUSICO algorithm for intersections with a lower load, $1 \mathrm{~km}$ or less apart. The article by Niittymaki and Nevala [17] summarizes the observations and results from the previous studies $[16,41,45,46]$ and develops the use of the FUSICO algorithm for traffic control in an area. 
The authors referred to the fact that the control system in the area is based on several parameters (duration of cycles on the intersections, duration of the intersection "go" signals, and the degree of the intersections' saturation), which can be suitably modelled using the fuzzy logic (block diagram of the control system in the area; see Figure 8). Moreover, the system in the area can also work in combination as centralized or decentralized one. In the centralized mode the adjustment of the cycle duration is based on the saturation degree of each intersection node; in the decentralized mode the distribution of the "go" signal and the preference of the public transport can be based on the evaluation of the traffic situation.

Niittymäki verified the results of the FUSICO scientific project in practice by implementation of the fuzzy control system ((FSC) "fuzzy signal controller") on LSE in the Finnish city of Oulunkylä [18]. The original solution of the intersection ("Vehicle Actuated") was compared with the fuzzy control system containing the HUTSIM microsimulation model. Though the tested intersection was simple direct intersection, the public transport lines were passing through it and it had a high intensity of vehicles and pedestrians during the traffic peaks hours. Four detectors in total (pick-up coils) were placed within 40 to 60 meters in front of the stop line. The FC-2000 controller, connected through a parallel interface into a PC, containing an FUSICO algorithm and a HUTSIM microsimulation software (wiring block diagram see Figure 9), was used for the fuzzy control system.

The results showed that the fuzzy control systems exceeded the conventional control systems in all parameters determining the quality of control, time of travel, number of stops, and the length of column.

Niittymäki and Könönen [47] Niittymäki and Mäenpää [48] focused together on the issue of the public transport preference on the LSE. The previously proposed multistage fuzzy control algorithm [16] was expanded by a basis of rules for preference of the public transport on a selected intersection (Figure 10). The control algorithm was verified during a practical implementation in cities of Vantaa, Lahti, and Jyväskylä, comparing the control prior and after the installation of the fuzzy system for the public transport preference.

In the article [49] the authors Niittymäki, Könönen further worked on the control systems containing fuzzy logic they proposed. In the publication [49] they tested and compared two different methods of LSE fuzzy control. One of the goals of the article was also the introduction of a new method leading to a higher quality and stability of the LSE fuzzy control system.

Niittymäki summarized all his discoveries in the thesis "Fuzzy Traffic Signal Control: Principles and Applications" [50], which was the peak of his scientific effort at that time. In his thesis, Niittymäki dealt in detail with the selection and design of a fuzzy system, selection of the input values into the system, and analysis and testing of various methods and approaches. The thesis contains detailed description of the FUSICO algorithm and software, which is designed for intersection control in the real traffic. The control systems were tested on selected intersections in Finland $[18,48]$.

Niittymäki and his colleagues summarized their further research in an article [51], comparing the usability of the

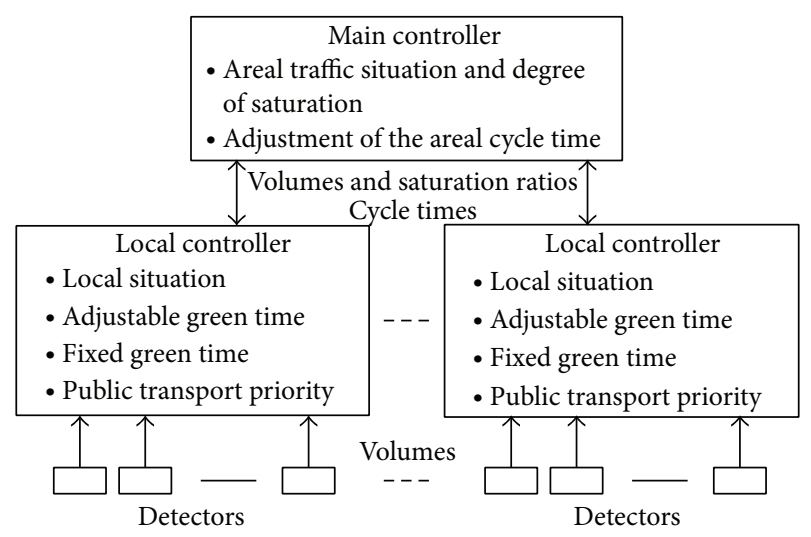

FIGURE 8: Block diagram of the application of fuzzy control in the traffic area [17].

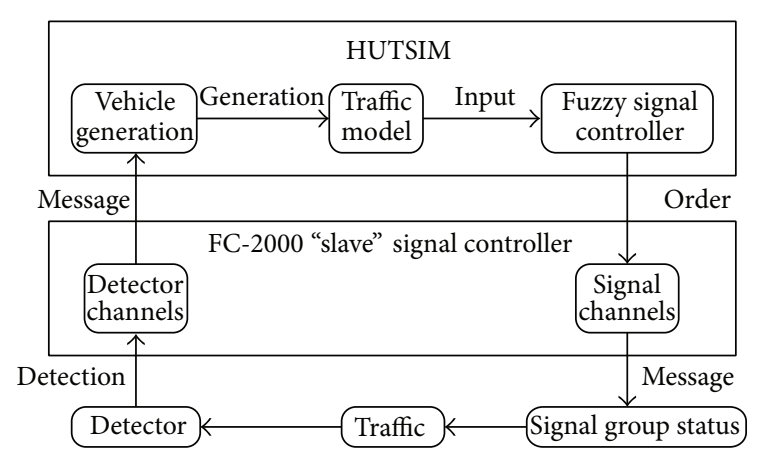

FIGURE 9: Block diagram of the fuzzy control system [18].

fuzzy inference method "Maximal Fuzzy Similarity" with the traditional Mamdani inference in the traffic control system (selection and extension of LSE phases). Both inference methods were compared in the HUTSIM microsimulation software. The analysis resulted in the conclusion that Mamdani type control is more suitable for low and medium intensities, while the "Similarity" method is more suitable for intersections with higher loads.

The simulations in the HUTSIM application were also used in the publication [52] in which Niittymäki and Turunen tested a new algorithm containing Łukasiewicz's multivalue logic on three real traffic control systems. The new control system was compared with the results from the Mamdani type control system with the inference method implemented in the MATLAB application fuzzy toolbox. The control systems were applied on a controlled pedestrian crossing and on a multistage control system containing a phase selection at a fork intersection with an LSE. The simulations in the HUTSIM application showed that the results were almost identical, and the new control system brought better results only in case of higher density of the traffic flow.

The method of fuzzy decision making for intelligent traffic control and warning system was patented in the North America in 2001. This should warn the drivers of the congestions [53]. The method was based on the use of at least one control unit, one intelligent switch, and intelligent 


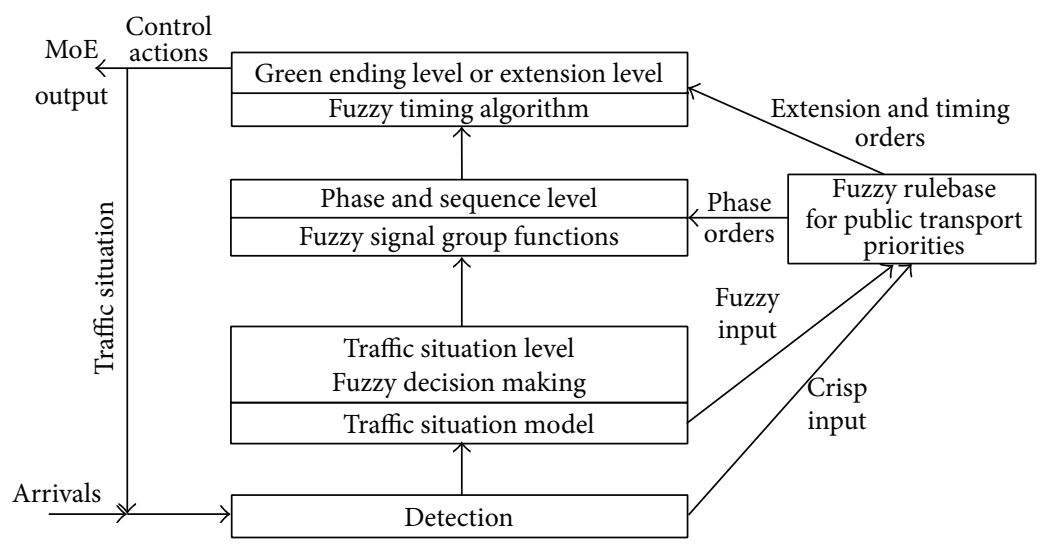

FIGURE 10: Multistage fuzzy control system with a fuzzy "block" public transport preference control [16].

central regulator. It is also assumed that every vehicle of the warning unit is able to receive data from the central control unit according to its position and is able to choose selectively the warning messages for the drivers.

The author Ella Bingham [54] from Finland was in her master thesis inspired by the publication by Kagolanu et al. [13] from 1995. She was among the first authors who dealt with the merger of fuzzy logic and Neural networks in the LSE control system. As early as in the late 1990s she described a traffic control neurofuzzy system in her thesis [54] upon which she presented on the publication [19] in 2002 where the Neural network set the type and location of the relevance function of the fuzzy regulator Figure 11. The proposed control system simulated in the HUTSIM application decreased the time delay of the vehicles in case of a constant loading of the intersection in question.

In relation to the articles [15, 42], the article [55] by Teodorovic et al. of 2001 deals with the merger of the fuzzy logic and genetic algorithms. The authors proposed a twophase process of the control system of an isolated intersection with LSE. In the first step the optimal sequence of phases was established based on the evaluation of the vehicle approach and determined using the genetic algorithm. In the second step the definition of the fuzzy rules was established based on the future traffic situation.

The authors Wei et al. proposed in their work [20] a multistage traffic control system for an isolated intersection with LSE (block diagram, see Figure 12). The proposed control system adjusted the duration of individual phases, extended or terminated phases, and selected the sequence of phases based on on-line data collection. The so-called "emergency step" caused by an increased demand for green light from a certain input was inserted into the system. The authors proposed in their article a flexible fuzzy control system with optional adjustment (tuning) of the input variable using a selected set of parameters (e.g., setting of the fitness function). The set of parameters was determined by a multicriteria optimizing genetic algorithm (MOGA) used also in the article [42]; the purpose of this algorithm was to find the optimal solution for frequently conflicting requests. According to the authors the system set this way showed decrease of time delays of vehicles

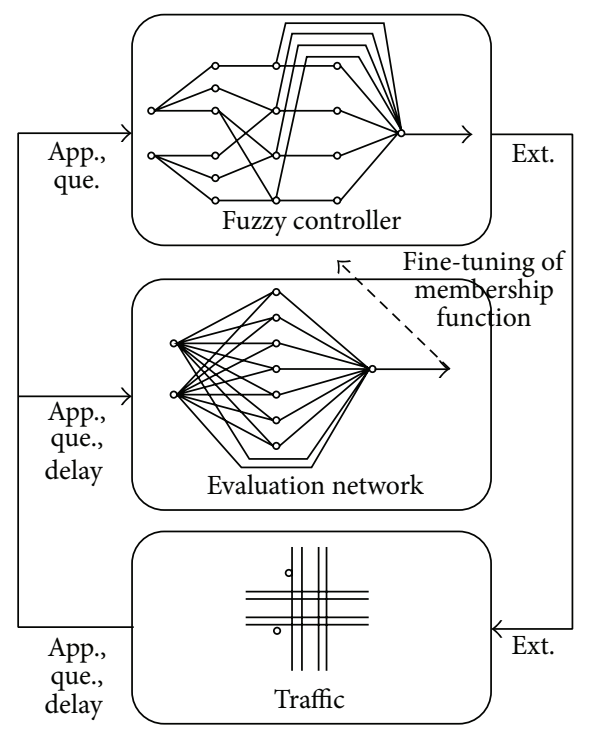

FIGURE 11: Block diagram of the neurofuzzy traffic control system [19].

and the number of stops, compared to the LSE dynamic control.

The basic idea of the article [20] was further expanded upon by Wei and Zhang in their publication [21] where the prediction of parameters used as inputs for the fuzzy logic itself provides the already described fuzzy-Neural network (the diagram of four-level fuzzy Neural network, see Figure 13).

The first level of the Neural network processed sharp values of the input variable whose output was also a sharp value. The second layer of the Neural network calculated parameters of the fitness functions (positions in the universum). The authors of the article called the third level "the rules' level." Each of the nodes of the third level represented one of the fuzzy rules. The last (fourth) level was the defuzzification level with a sharp value of a selected output variable.

The authors Wei and Wang further presented on the idea of a three-level LSE control system in the publication [22] 


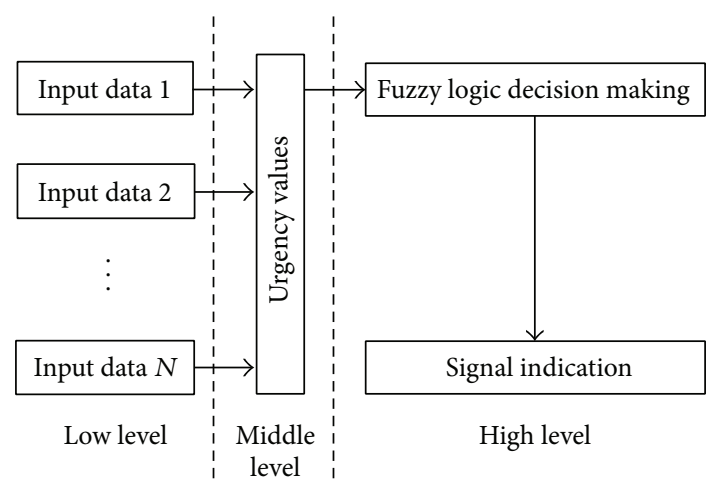

FIgURE 12: Three levels of traffic signal control [20].

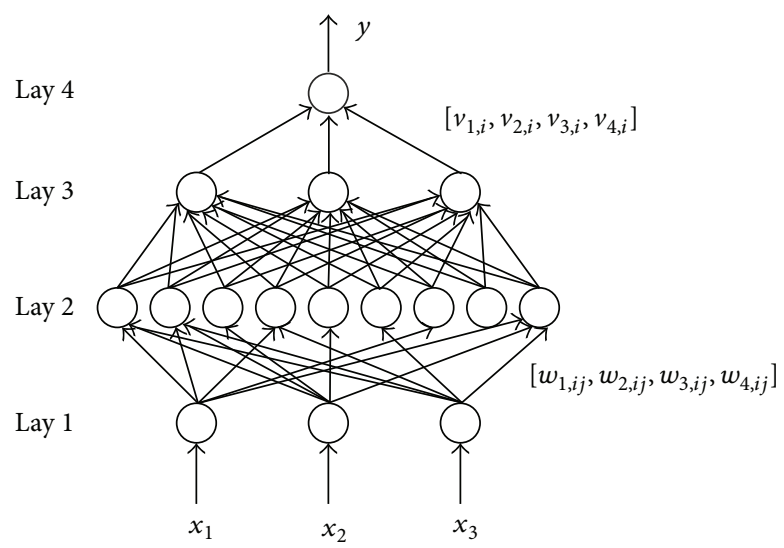

Figure 13: Four-level fuzzy-Neural network diagram [21].

of 2003. For the block diagram of a modified and expanded three-level LSE control system, see Figure 14.

The main change consisted of the expansion of the lowest level by a module, which predicted a value of the input variable using the fuzzy Neural network. The authors moved the fuzzy inference system from the highest level to the second (middle) level. According to the authors a system assembled in this way solves the issues of stochastic traffic systems, such as an intersection with LSE, much better.

Kuo and Lin proposed in their publication [23] a new approach for determination of an LSE signal plan based on fuzzy logic (block diagram of the process, see Figure 15).

Based on the vehicle detection in the intersection area first the secondary input variables were assessed ("width" of the intersection and longitudinal slope of the intersection lanes), which served to trigger the selected cases 1 to 4 . The combination of main input variables detected during the cycle (average speed, congestion factor, and vehicle position) further triggered the defined rules. The defuzzification process resulted in the appropriate setting of the LSE signal plan. From the system design it is obvious that the authors expanded the number of input variables by input variables reflecting the geometry of the intersection and the vehicle position determined based on the distance from the intersection stop line.

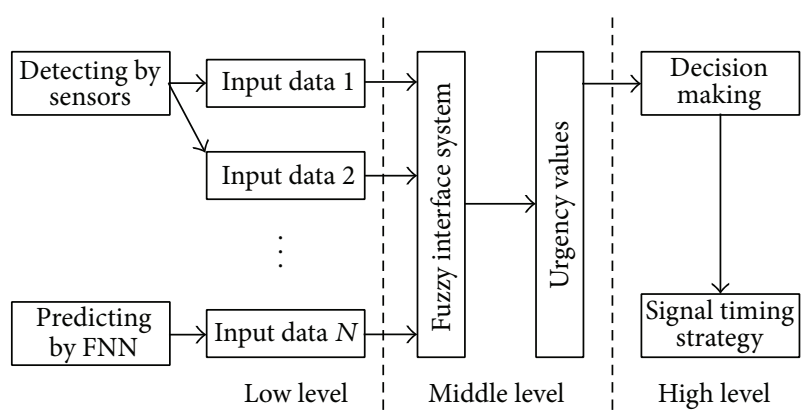

FIGURE 14: Three levels of LSE traffic control system [22].

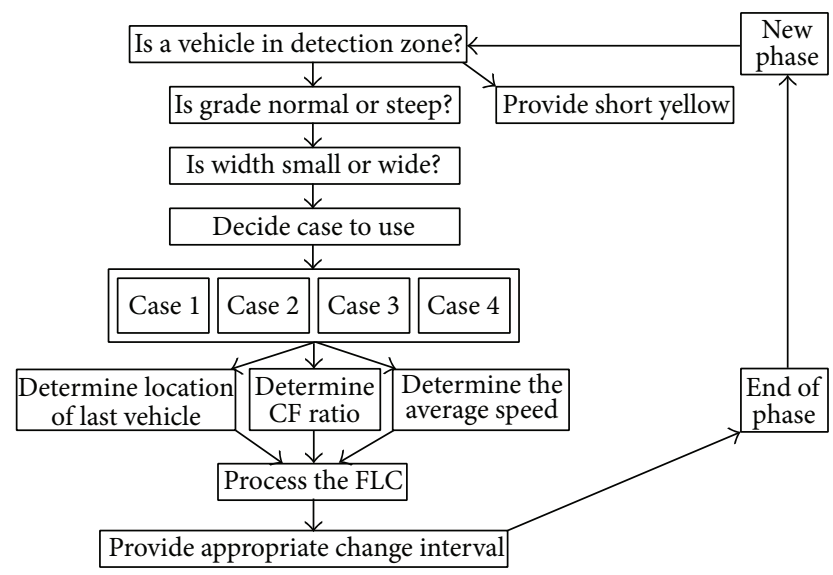

FIGURE 15: Block diagram of the control process (graphic representation of system process) [23].

Murat and Gedizlioglu [24] developed a fuzzy control system for an isolated intersection, which differed from the above mentioned systems by the use of two fuzzy control systems. The first fuzzy system "fuzzy logic signal time controller" decided on the signal plan duration modification (extension of phases). The second fuzzy system "fuzzy logic phase sequencer" determined the sequence and number of phases. Each of the fuzzy systems contained a different database (block diagram of the LSE control system see Figure 16). The authors elaborated on the above mentioned control system in the article [56] where they proposed a fuzzy control system for a multiphase LSE, "logic multi-phased signal control (FLMuSiC)."

Jacques et al. [57] analyzed the theoretical aspects of the decision-making logic applied in the LSE control system. In practice they tested three different fuzzy control systems (the difference was in the application of three different methods of defuzzification (MOM, COG, and SOM)) on an isolated intersection for three different loading levels (low, medium, and high).

Expert publications dedicated to the application of fuzzy algorithms in the LSE control system after the year 2002 do not bring entirely new ideas; they mostly focus either on improvement of algorithms of other authors or on certain expansion of the control systems. 


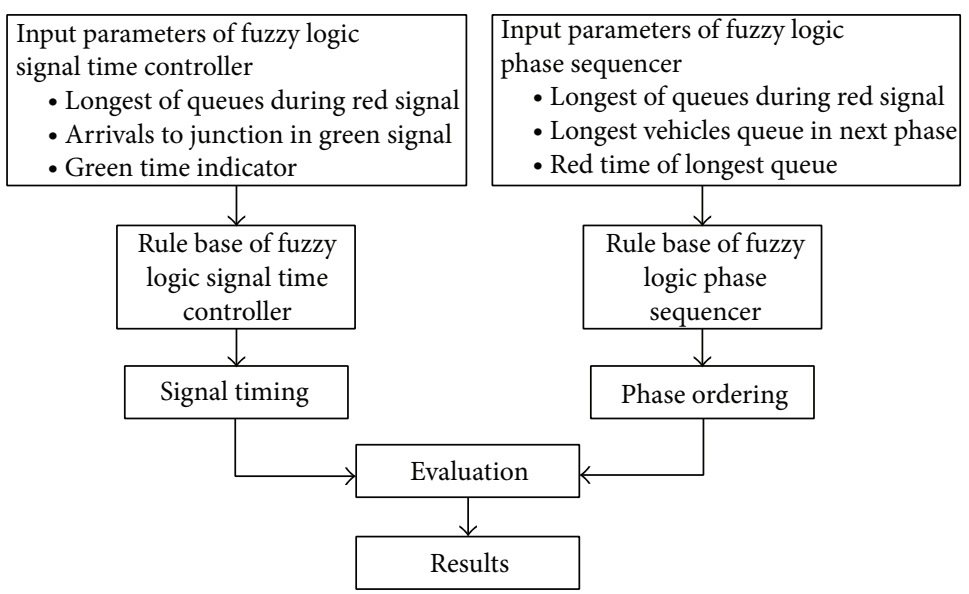

FIGURE 16: Block diagram of the LSE fuzzy control system [24].

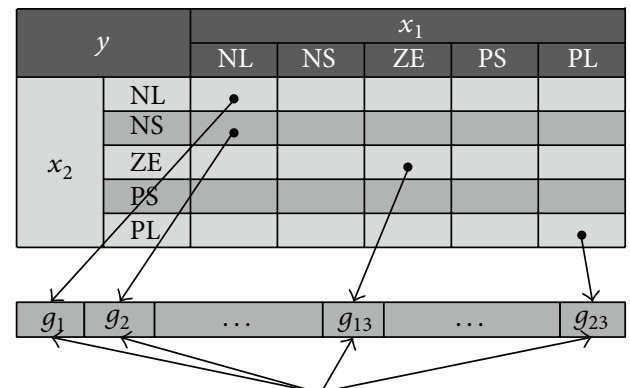

(0) Not included

(1) $\gamma$-NL

(2) $\gamma$-NS

(4) $\gamma$-PS

(5) $\gamma$-PL

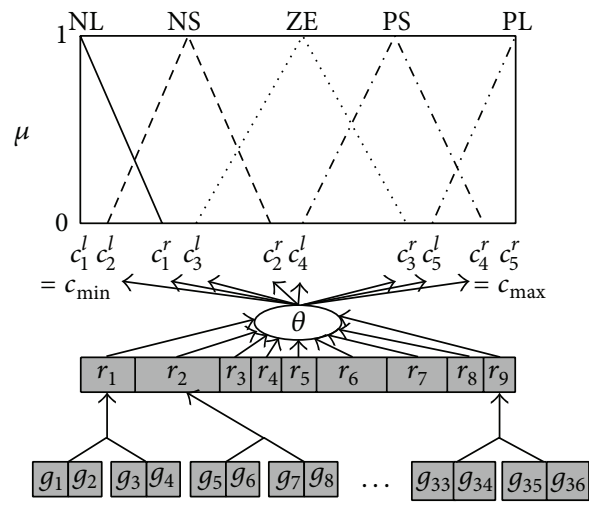

Note: $g_{1}=0 \sim 9$

FIGURE 17: Illustration of the fuzzy rule and fitness function selection using the genetic algorithm [25].

One of the other articles dealing with the application of the fuzzy algorithm in the LSE control system in combination with the genetic algorithm is the thesis by Chiou and Lan [25]. The research resulted in the proposal of an iteration evolution algorithm containing a genetic fuzzy control system ("genetic fuzzy logic controller (GFLC)"). The genetic algorithm should select a suitable fuzzy rule and set the fitness function (Figure 17). They tested the proposed intersection control system in Taipei (Thaiwan) and the test results showed that the "GFLC" control algorithm is sufficiently effective and robust for the use in LSE adaptive control systems.

In the 2009 article [58] Zeng et al. proposed a fuzzy control system for an isolated intersection where the value of the input variable for each phase would be determined in relation to the previous intensity values.

The authors Zhang et al. [59] introduced an interesting idea into the fuzzy control system. Their expert publication described the proposal of a two-level fuzzy control system for an overloaded transportation network. The transportation area in question had compact central areas in which the intensities reached high values with a threat of a possible occurrence of traffic congestions. The proposed fuzzy algorithm monitored two goals (aspects), which strove to prevent the traffic congestions ("anticongestion fuzzy algorithm (ACFA)"). The first goal was to minimize the delay of vehicles and the second goal was to prevent occurrence of traffic congestions. The first level of the fuzzy algorithm assessed the traffic situation in the network in question and the second level of the algorithm was to control the LSE on each intersection. The peripheral intersections were used to regulate the number of vehicles approaching the inner area by altering the vehicle direction (different selection of phase sequence). The result was the decrease in the probability of overloading the transportation network.

The authors $\mathrm{Hu}$ et al. also presented an interesting LSE control system in their 2007 article [26]. The proposed control system contains an evolution algorithm, which generates the optimal fuzzy rule base. The evolution algorithm working with real measured data was applied to an isolated four-arm intersection containing lanes for straight direction and right turns. Left turns were solved only in one intersection arm as a separate bypass. The proposed control system reflected the safety and quality of traffic when the efficiency of the control algorithm itself was defined using the "fitness" function. The authors defined the fitness function (performance function) 
as an average time loss of all vehicles in $\Delta t$. For the block diagram of the LSE control system containing a block for evaluation of the performance function, see Figure 18.

$\mathrm{Hu}$ et al. further elaborated on the idea of application of an advanced LSE control system in the following article [27]. Together with the other authors they proposed a hierarchic fuzzy control system, which was applied to a real fourarm intersection containing fourteen lanes, two pedestrian crossings, and 7 phases. The hierarchic control system contained seven input variables (column length) of seven phases and one input represented by a "go" signal duration for a selected phase. It is obvious from Figure 19 that the hierarchic control system contained six levels of control subprocesses (subcontrollers). Each of these individual control elements contained two inputs and one output. Levels 1 to 5 used two identical input parameters representing column lengths. The consolidated column length from the previous layer was the output. The last (sixth) level used the consolidated column length of previous levels and the column length of the selected phase as an input parameter. The output of the sixth level was the duration of the green light of the selected phase. The use of the evolution algorithm showed the $38 \%$ decrease of the vehicle waiting time.

Yang et al. [28] proposed in their article HFLC (hierarchical fuzzy logic controller); for the hierarchic fuzzy control system, see Figure 20. The proposed control system was a two-level one and contained three modules with fuzzy logic. The first level was represented by two modules with fuzzy logic, which estimated the actual duration of the green light and the subsequent red light phase based on the intensity of the traffic flow of the given phase. The second level contained one fuzzy module, which decided on the extension of the actual green phase. This proposed control system shows, according to the study conclusions, better control results than the previously used one-level LSE fuzzy control systems (single stage fuzzy logic controller (SSFLC)).

Authors Cheng and Yang proposed in their thesis [60] another LSE control system containing a fuzzy-genetic algorithm. They used fuzzy clustering analysis to create the knowledge base, which was created based on identified intensities. They separated the rules of the knowledge base into two sets, fixed and variable rules. The genetic algorithm was used for setting the set of variable rules during the LSE control and was also part of the process of determination of optimal cycle duration. The proposed control system provided again better results than the fixed signal plan or dynamic LSE control.

In their article [29] the authors Schmöcker et al. presented a multicriteria optimization control system using the fuzzy logic. The fitness function was optimized using the BellmanZdeh principle. According to the authors it was a very effective method due to the fact that the result led to the so-called Paret optimal solution (ideal balanced state). The fitness functions were further optimized through a genetic algorithm. For the block diagram of the transportation system, see Figure 21. The authors verified the proposed system on a case study of the Marylebone Road, Baker Street intersection in London.

$\mathrm{Li}$ and Zhang proposed in their article [30] a multiphase fuzzy control system, which is comprised of two parts: the first part composed of the so-called fuzzy green extension

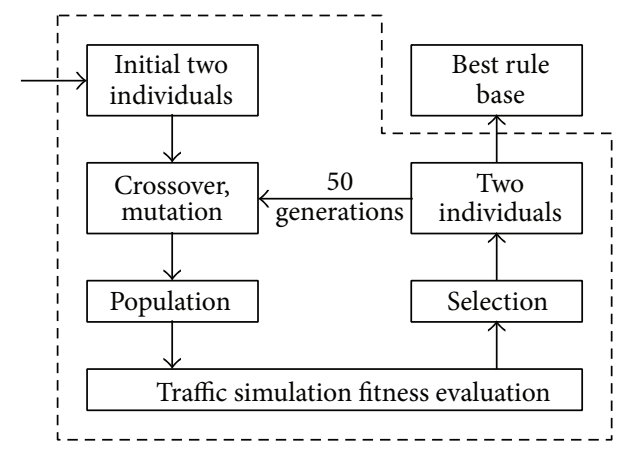

FIgURE 18: The block diagram of the genetic fuzzy generator database [26].

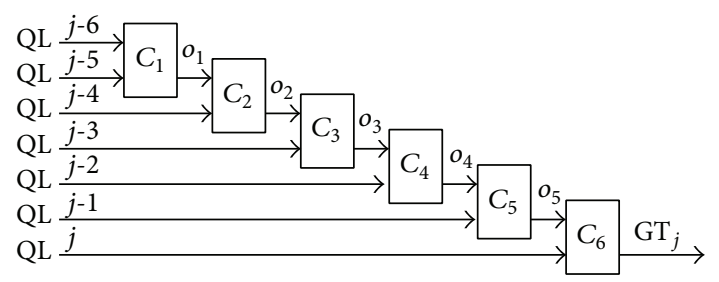

FIGURE 19: Diagram of the hierarchic fuzzy control system [27].

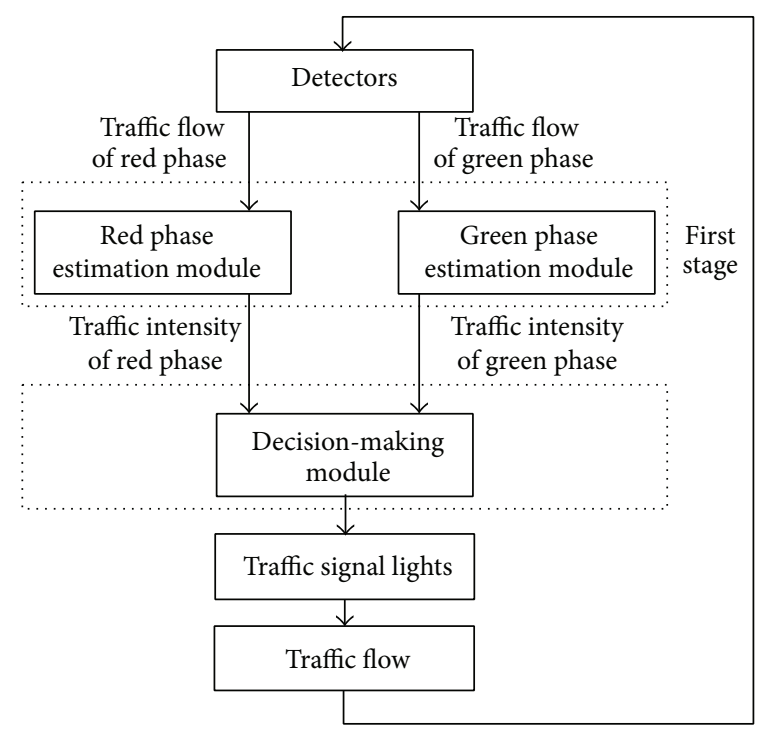

FIGURE 20: HFLC architecture (hierarchical fuzzy logic controller) [28].

controller (FGEC), and the second part provided the change of phases (fuzzy phase change controller (FPCC)) again using the fuzzy logic (block diagram, see Figure 22).

Zarandi and Rezapour [31] chose a different approach to multilevel fuzzy LSE control. The fuzzy control system contained a fuzzy system of phase selection and a fuzzy system for green extension; see Figure 23. The system either extended the current running phase or selected a new phase diagram.

The publication of Rhung et al. [32] is interesting because it uses Sugeno type fuzzy inference system instead of the usual Mamdani type fuzzy inference system. The M/M/1 queuing theory was also used in the model structure (see Figure 24). 


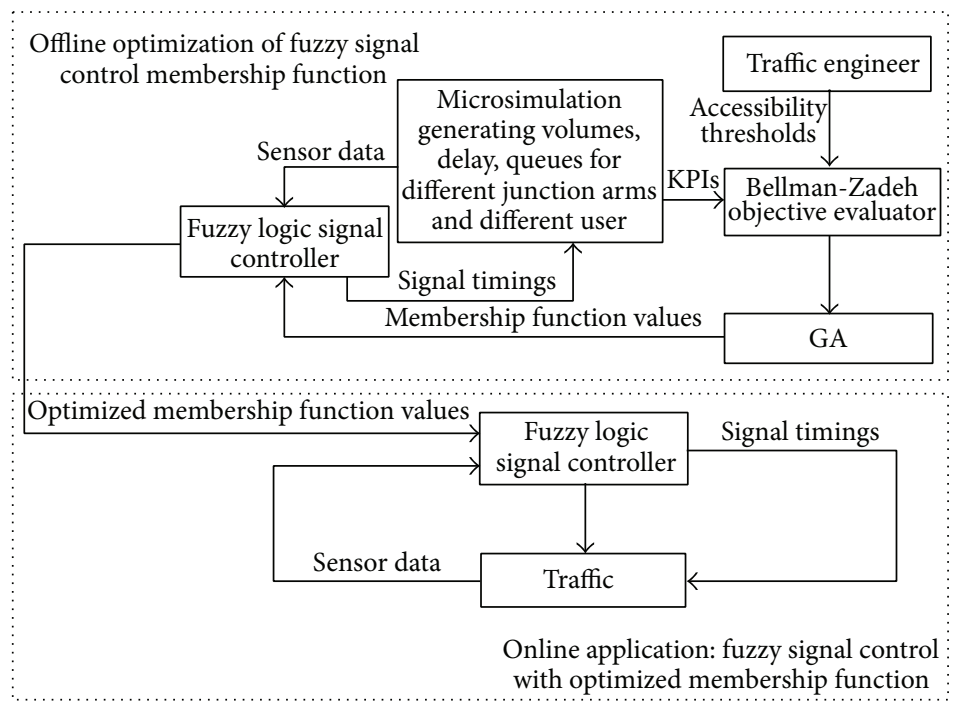

FIGURE 21: Block diagram of the transportation system [29].

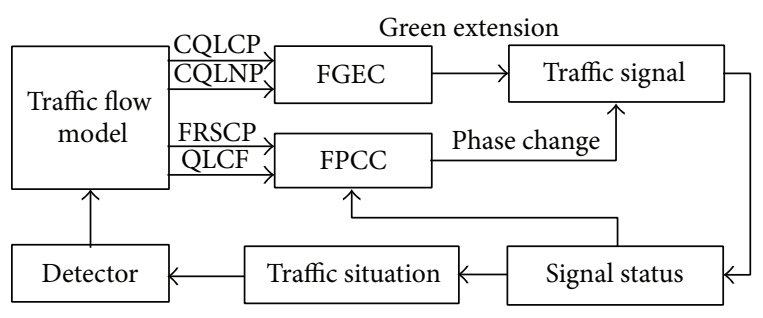

FIGURE 22: Block diagram of the fuzzy control system [30].

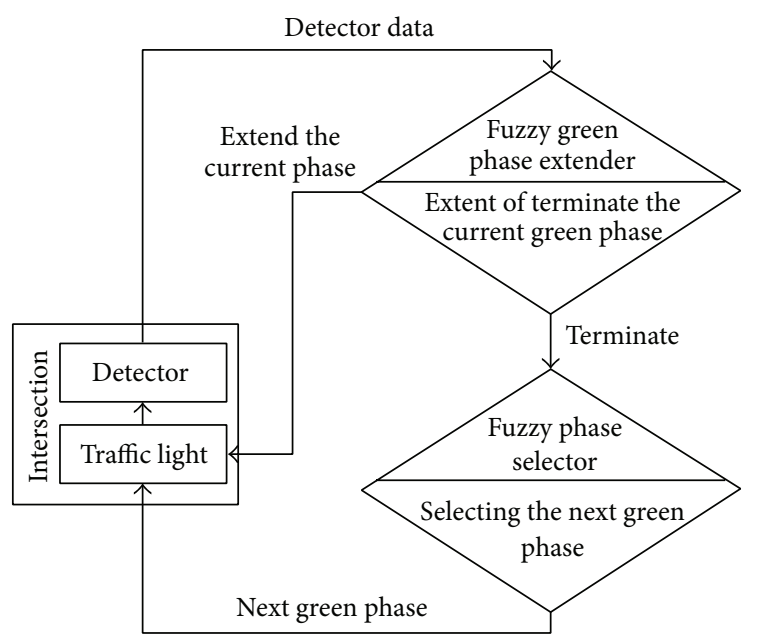

FIGURE 23: Block diagram of the multilevel LSE fuzzy control system [31].

Wen et al. in their publication [6] dealt with a proposal of a stochastic control system based on a fuzzy reinforcement learning system ("fuzzy reinforcement learning" $(F R L)$ ). The authors claim that this system (Figure 25) can adapt to fluctuating traffic load (intensity, vehicle direction) and prevent oversaturation of the intersection. The proposed

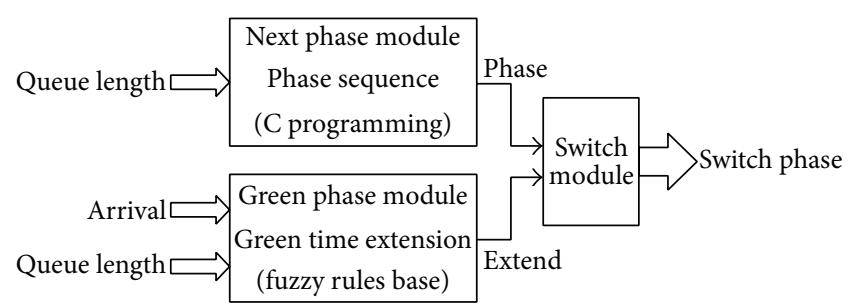

FIGURE 24: Block diagram of the control system [32].

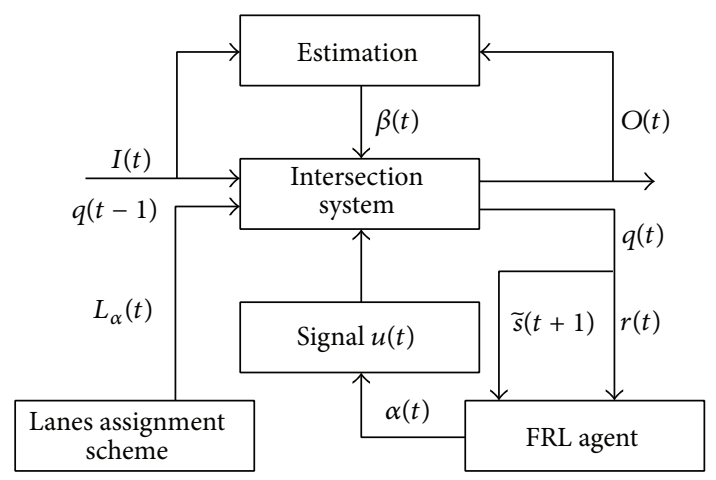

FIGURE 25: Block diagram of the "FRL" system of intersection control [6].

control system was tested at a four-arm intersection and was compared with control system using the fixed signal plan and with fully dynamic LSE control system. The analysis of the results of the performed simulations showed better performance of "FRL" system (decrease of average time delay of $25.7 \%$ ) as compared with the traditional control systems, especially in case of oversaturation of the intersection caused by the increase of the traffic demand.

Chen et al. [61] followed the idea of FLR in 2009. They involved the Level of Service (LOS) methodology to the 
system. The traffic in China can be characterized by big amount of pedestrians and cyclists, who slow down the traffic flow. Fuzzy control system with methodology LOS is influenced by the forecast of user's behaviour, which helps to improve the process of fuzzification. It takes into account the driver's preferences, for example, longer green phase or shorter intervals.

Niittymaki and Kikuchi [41] deal in their paper with specifications of pedestrian crossings at intersections, where the pedestrians prevail. Using the fuzzy logic the traffic control system became the so-called pedestrian friendly.

In the article [33] the authors proposed a hybrid LSE control system combining fuzzy logic, learning automata, and CPN (coloured Petri nets). The system was based on a learning automata (block diagram, see Figure 26), where input data changed its internal settings and chose selected output action. Fuzzy coloured Petri net should predict optimized future system conditions.

In the recent study [62] concern was devoted to exploitation of neural networks for better prediction of traffic behaviour. It turned out that neural networks describe, in a natural way, driver's behaviour and allow better decision on traffic control and optimization of light signalling. However, the use of fuzzy logic for control of LSE is not limited to four-arm or T intersections; it can be used to control rotary intersection, as suggested in the article [63] by Gong et al. This article compared three different fuzzy control systems:

(i) FUZZY-TIM: fuzzy logic setting the duration of the green of individual phases;

(ii) FUZZY-SEQ: fuzzy logic modifying the phase sequence;

(iii) FUZZY-MIX: combination of the two previous control systems (two-level fuzzy control system).

Lu et al. improved in their paper [64] from 2010 the fuzzy logic of a roundabout. The roundabouts are very popular in the USA, but it is almost impossible for pedestrians, especially the handicapped ones, to judge the safe space between the vehicles. They rely on hearing, but the surrounding noise makes it more complicated. The result is that the traffic lights are also installed at the roundabouts, and it showed that the so-called "distant" layout makes the delay of the pedestrians much smaller and the same time keeps the vehicles in movement. This dynamic system was tested in different traffic flows and results were excellent.

Another score of articles combining fuzzy logic and genetic algorithm is the 2011 publication by [65]. The article proposes an off-line GA, which should optimize the fuzzy rules and fitness functions of GPS variables (green phase selector) and GTA (green-time adjustor) where the fitness function was the $\mathrm{AD}$ (average delay) variable.

The article [34] is an interesting work where the authors compared LSE fuzzy control system they proposed with several different LSE control systems (Mamdani type FIS, Sugeno type FIS, HCM, and Webster). It was a relatively complex review of the LSE fuzzy control issue. The system innovation represented the use of feedback for setting the fitness function (see Figure 27).

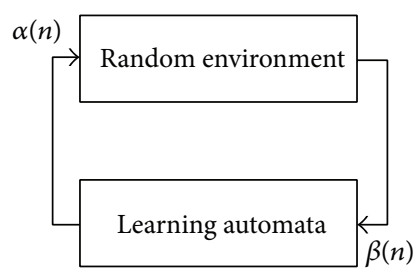

FIGURE 26: Relationship between learning automata and their environment [33].

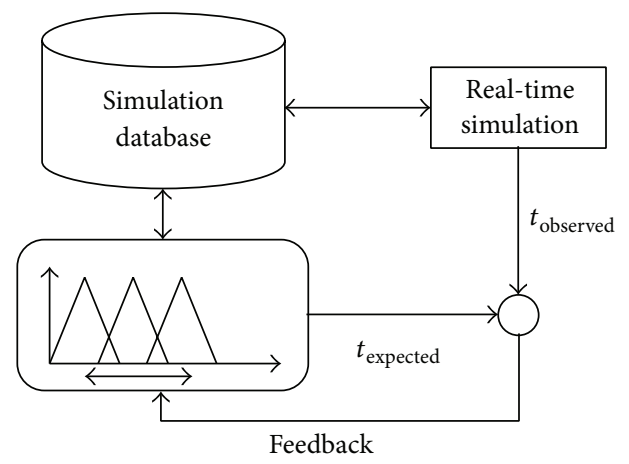

FIGURE 27: Illustration of the feedback within the control system [34].

Another series of articles combining the genetic algorithm and fuzzy logic for four-arm intersection control with LSE is the publication [35] by Ma et al. The authors proposed a multiphase fuzzy control system, this time containing online genetic algorithm for optimizing of the fitness function. The control system used a database of historically measured (in previous steps) traffic engineering data. The article also contained a block diagram illustrating the optimizing process using the genetic algorithm (Figure 28).

Yang et al. proposed in their article [36] a two-level fuzzy control system containing a hybrid genetic algorithm (block diagram of the control system, see Figure 29). The online hybrid GA was supposed to optimize the fitness function and control rules. As in the previous case the authors used for control the historically measured data (the state they used quasi data, without closer specification of the term). The use of an emulator of the traffic flow in the LSE control system was a new element (without including the proposal of proprietary GA).

\section{Summary and Future Challenges}

In this paper, we have conducted a comprehensive review of the literature dealing with the use of fuzzy sets and fuzzy logic theory in the field of traffic control systems. The review focused on various approaches which describe and predict the driver's behaviour and optimize the flow of the traffic. The first works published in the late 1970s of the 20th century showed the possibility of using the vague description of the traffic state and using it for precise decision and control of light signalling. In the course of development there was a rise in works taking into account more complex systems and also 


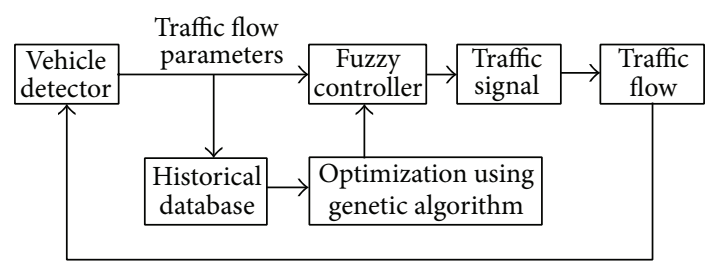

FIGURE 28: Block diagram of the multiphase fuzzy control system [35].

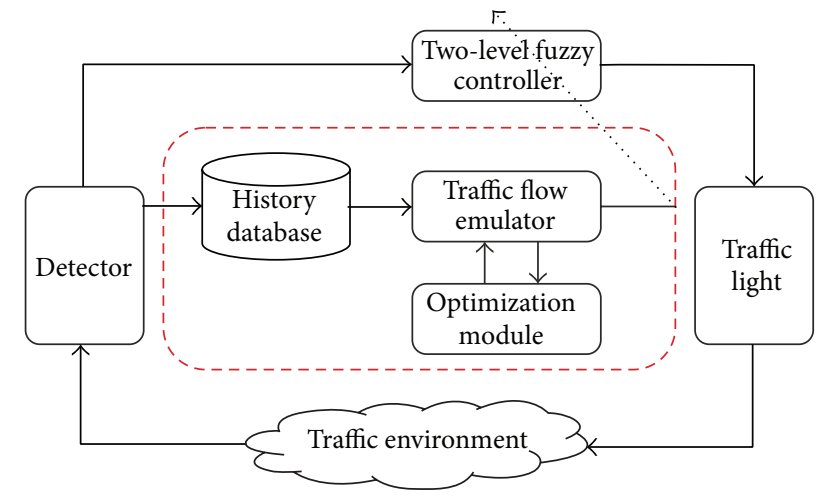

FIGURE 29: Block diagram of two-level fuzzy control system containing hybrid GA [36].

more theories. The review covers all the above-mentioned approaches and discusses, to some extent, the advantages and drawbacks of the proposed models. Many studies involved comparison with the real datasets and proved the advantages of the exploitation of fuzzy sets and fuzzy logic.

Based on the literature survey, there are still open questions and issues that can be addressed in the near future studies. The challenges involve (i) the control of large number of crossroads simultaneously to ensure the continuous flow of the traffic especially in cases of traffic jams, (ii) the use of modern UAV based data collection and rapid mapping methods to avoid the traffic jams, (iii) the introduction of parameters describing situations of emergency when traffic accident occurs, (iv) the introduction of large sensors networks involving also the nonstandard parameters (driver mood, drastically changing weather, etc.), (v) the optimization of neural networks for description of traffic and their combination with fuzzy logic, and (vi) the use of robotic vehicles without drivers.

\section{Conflict of Interests}

The authors declare that there is no conflict of interests regarding the publication of this paper.

\section{Acknowledgments}

The study has been supported by the Education for Competitiveness Operational Program, European Social Fund (Project CZ.1.07/2.3.00/20.170 of the Ministry of Education, Youth and Sports of the Czech Republic), and by the Project 14-26831S of the Czech Science Foundation.

\section{References}

[1] K. K. Tan, M. Khalid, and R. Yusof, "Intelligent traffic lights control by fuzzy logic," Malaysian Journal of Computer Science, vol. 9, no. 2, pp. 29-35, 1996.

[2] M. Hanss, Applied Fuzzy Arithmetic: An Introduction with Engineering Applications, Springer, Berlin, Germany, 2005.

[3] A. Kaufmann and M. M. Gupta, Introduction to Fuzzy Arithmetic, Van Nostrand Reinhold Company, New York, NY, USA, 1985.

[4] G. C. D’Ans and D. C. Gazis, "Optimal control of oversaturated store-and-forward transportation networks," Transportation Science, vol. 10, no. 1, pp. 1-19, 1976.

[5] R. Boettger and Siemens, "Optimal coordination of traffic signals in street networks," in Proceedings of the 5th International Symposium on the Theory of Traffic Flow and Transportation, Berkeley, Calif, USA, June 1971.

[6] K. Wen, W. Yang, and S. Qu, "A stochastic adaptive traffic signal control model based on fuzzy reinforcement learning," in Proceedings of the 2nd International Conference on Computer and Automation Engineering, ICCAE '10), pp. 467-471, February 2010.

[7] C. Pappis and E. Mamdani, "A fuzzy logic controller for a traffic junction," IEEE Transactions on Systems, Man and Cybernetics, vol. 10, pp. 707-717, 1977.

[8] E. H. Mamdani, "Application of fuzzy logic to approximate reasoning using linguistic synthesis," Fuzzy Sets and Systems, vol. 26, no. 12, pp. 1182-1191, 1977.

[9] M. Nakatsuyama, H. Nagahashi, and N. Nishizuka, "Fuzzy logic phase controller for traffic junctions in the one-way arterial road," in Proceedings of the IFAC 9th Triennial World Congress, pp. 2865-2870, Budapest, Hungary, 1984.

[10] R. Bisset and L. Kelsey, "Simulation of traffic flow and control using conventional, fuzzy, and adaptive methods," in Proceedings of the European Simulation Multiconference, York, UK, 1992.

[11] R. Kelsey, K. Bisset, and M. Jamshidi, "A simulation environment for fuzzy control of traffic systems," in Proceedings of the 12th IFAC-World Congress, Sydney, Austria, 1993.

[12] J. Favilla, A. Machion, and F. Gomide, "Fuzzy traffic control: adaptive strategies," in Proceedings of the 2nd IEEE International Conference on Fuzzy Systems, vol. 1, pp. 505-511, San Francisco, Calif, USA, 1993.

[13] K. Kagolanu, R. Fink, H. Smartt, R. Powell, and E. Larson, "An intelligent traffic controller," in Proceedings of the 2nd World Congress on Intelligent Transportation Systems, 1995.

[14] G. Beauchamp-Baez, E. Rodriguez-Morales, and E. L. MunizMarrero, "A fuzzy logic based phase controller for traffic control," in Proceedings of the 6th IEEE International Conference on Fussy Systems, pp. 1533-1539, July 1997.

[15] T. H. Heung and T. K. Ho, "Hierarchical fuzzy logic traffic control at a road junction using genetic algorithms," in Proceedings of the IEEE International Conference on Fuzzy Systems Proceedings; IEEE World Congress on Computational Intelligence, vol. 2, pp. 1170-1175, Anchorage, Alaska, USA, May 1998.

[16] J. Niittymäki and M. Pursula, "Signal control using fuzzy logic," Fuzzy Sets and Systems, vol. 116, no. 1, pp. 11-22, 2000.

[17] J. Niittymaki and R. Nevala, "Fuzzy adaptive traffic signal control-principles and results," in Proceedings of the Joint 9th IFSA World Congress and 20th NAFIPS International Conference, vol. 5, pp. 2870-2875, 2001. 
[18] J. Niittymäki, "Installation and experiences of field testing a fuzzy signal controller," European Journal of Operational Research, vol. 131, no. 2, pp. 273-281, 2001.

[19] E. Bingham, "Reinforcement learning in neurofuzzy traffic signal control," European Journal of Operational Research, vol. 131, no. 2, pp. 232-241, 2001.

[20] W. Wei, Y. Zhang, J. B. Mbede, Z. Zhang, and J. Song, "Traffic signal control using fuzzy logic and MOGA," in Proceedings of the IEEE International Conference on Systems, Man, and Cybernetics, vol. 2, pp. 1335-1340, 2001.

[21] W. Wei and Y. Zhang, "FL-FN based traffic signal control," in Proceedings of the IEEE International Conference on Fuzzy Systems (FUZZ-IEEE '02), vol. 1, pp. 296-300, Honolulu, Hawaii, USA, 2002.

[22] W. Wei and M.-J. Wang, "Fuzzy-MOGA-based traffic signal control at intersection," in Proceedings of the International Conference on Machine Learning and Cybernetics, vol. 1, pp. 639644, November 2003.

[23] K. Y. Kuo and J. Lin, "Application of fuzzy set theory to the change intervals at a signalized intersection," Fuzzy Sets and Systems, vol. 129, no. 3, pp. 387-403, 2002.

[24] Y. S. Murat and E. Gedizlioglu, "A new approach for fuzzy traffic signal control," in Proceedings of the 13th Mini-EURO Conference on Artificial Intelligence in Transportation Systems and Science, Bari, Italy, 2002.

[25] Y.-C. Chiou and L. W. Lan, "Adaptive traffic signal control with iterative genetic fuzzy logic controller (GFLC)," in Proceedings of the IEEE International Conference on Networking, Sensing and Control, pp. 287-292, Taipei, Taiwan, 2004.

[26] Y. Hu, P. Thomas, and R. J. Stonier, "Traffic signal control using fuzzy logic and evolutionary algorithms," in Proceedings of the IEEE Congress on Evolutionary Computation (CEC '07), pp. 1785-1792, September 2007.

[27] Y. Hu, A. Chiou, and Q. Han, "Hierarchical fuzzy logic control for multiphase traffic intersection using evolutionary algorithms," in Proceedings of the IEEE International Conference on Industrial Technology (ICIT '09), pp. 1-6, Gippsland, Australia, February 2009.

[28] Z. Yang, X. Huang, C. Du, M. Tang, and F. Yang, "Hierarchical fuzzy logic traffic controller for urban signalized intersections," in Proceedings of the 7th World Congress on Intelligent Control and Automation (WCICA'08), pp. 5197-5202, Chongqing, China, June 2008.

[29] J.-D. Schmöcker, S. Ahuja, and M. G. H. Bell, "Multi-objective signal control of urban junctions-framework and a London case study," Transportation Research Part C: Emerging Technologies, vol. 16, no. 4, pp. 454-470, 2008.

[30] J. Li and H. Zhang, "Study on optimal control and simulation for urban traffic based on fuzzy logic," in International Conference on Intelligent Computation Technology and Automation (ICICTA '8), vol. 1, pp. 936-940, 2008.

[31] M. H. F. Zarandi and S. Rezapour, "A fuzzy signal controller for isolated intersections," Journal of Uncertain Systems, vol. 3, no. 3, pp. 174-182, 2009.

[32] L. G. Rhung, A. C. Soh, R. Z. A. Rahman, and M. K. Hassan, "Fuzzy traffic light controller using Sugeno method for isolated intersection," in Proceedings of the IEEE Student Conference on Research and Development (SCOReD '09), pp. 501-504, November 2009.

[33] S. Barzegar, M. Davoudpour, M. R. Meybodi, A. Sadeghian, and M. Tirandazian, "Traffic signal control with adaptive fuzzy coloured Petri net based on learning automata," in Proceedings of the Annual Meeting of the North American Fuzzy Information Processing Society (NAFIPS '10), pp. 1-8, 2010.

[34] A. Aksaç, E. Uzun, and T. Özyer, "A real time traffic simulator utilizing an adaptive fuzzy inference mechanism by tuning fuzzy parameters," Applied Intelligence, vol. 36, no. 3, pp. 698720, 2012.

[35] W. Ma, D. Geng, and Y. Yan, "Multi-phase fuzzy control of single intersection in traffic system based on genetic algorithm," International Journal of Innovative Computing Information and Control, vol. 8, no. 5, pp. 1349-4198, 2012.

[36] W. Yang, L. Zhang, Z. He, and L. Zhuang, "Optimized two-stage fuzzy control for urban traffic signals at isolated intersection and Paramics simulation," in Proceedings of the 15th International IEEE Conference on Intelligent Transportation Systems (ITSC '12), pp. 391-396, Anchorage, Alaska, USA, 2012.

[37] R. Hoyer and U. Jumar, "Fuzzy control of traffic lights," in Proceedings of the 3rd IEEE Conference on Computing \& Processing (Hardware/Software), pp. 1526-1531, June 1994.

[38] S. Kim, Applications of petri metworks and fuzzy logic to advanced traffic management systems [Ph.D. thesis], Polytechnic University, New York, NY, USA, 1994.

[39] T. M. Sayers, M. G. H. Bell, T. Mieden, and F. Busch, "Improving the traffic responsiveness of signal controllers using fuzzy logic," in Proceedings of the IEE Colloquium on Urban Congestion Management, pp. 6/1-6/4, London, UK, 1995.

[40] J. Kim, "A fuzzy logic control simulator for adaptive traffic management," in Proceedings of the 6th IEEE International Conference on Fuzzy Systems, vol. 3, pp. 1519-1524, 1997.

[41] J. Niittymaki and S. Kikuchi, "Application of fuzzy logic to the control of a pedestrian crossing signal," Transportation Research Record, no. 1651, pp. 30-38, 1998.

[42] T. Sayers, J. Anderson, and M. Bell, "Traffic control system optimisation: a multiobjective approach," in Mathematics in Transport Planning and Control, Proceedings of the 3rd IMA International Conference on Mathematics in Transport Planning and Control, pp. 37-46, Pergamon, Elsevier Science, London, UK, 1998.

[43] M. B. Trabia, M. S. Kaseko, and M. Ande, "A two-stage fuzzy logic controller for traffic signals," Transportation Research Part C: Emerging Technologies, vol. 7, no. 6, pp. 353-367, 1999.

[44] J. Niittymäki, "Using fuzzy logic to control traffic signals at multi-phase intersections," in Computational IntelligenceTheory and Applications. International Conference, B. Reusch, Ed., vol. 1625 of Lecture Notes in Computer Science, pp. 354-362, Springer, Berlin, Germany, 1999.

[45] J. Niittymäki, "General fuzzy rule base for isolated traffic signal control-rule formulation," Transportation Planning and Technology, vol. 24, no. 3, pp. 227-247, 2001.

[46] J. Niittymaki, "Fuzzy logic two-phase traffic signal control for coordinated one-way streets," in Proceedings of the IEEE Midnight-Sun Workshop on Soft Computing Methods in Industrial Applications (SMCia '99), pp. 69-74, Kuusamo, Finland, 1999.

[47] J. Niittymäki and V. Könönen, "Traffic signal controller based on fuzzy logic," in Proceedings of the IEEE International Conference on Systems, Man, and Cybernetics, vol. 5, pp. 3578-3581, Nashville, Tenn, USA, 2000.

[48] J. Niittymäki and M. Mäenpää, "The role of fuzzy logic public transport priority in traffic signal control," International Journal of Traffic Management and Transportation Planning, vol. 42, pp. 22-26, 2001. 
[49] V. Könönen and J. Niittymaki, "New methods for traffic signal control-development of fuzzy controller," in Proceedings of the 9th IEEE International Conference on Fuzzy Systems (FUZZ IEEE '00), vol. 1, pp. 358-362, San Antonio, Tex, USA, May 2000.

[50] J. Niittymäki, Fuzzy traffic signal control (principles and applications) [Ph.D. thesis], Helsinki University of Technology Transportation Engineering Publication, Helsinki, Finland, 2002.

[51] J. Niittymäki, R. Nevala, and E. Turunen, "Fuzzy traffic signal control and a new interface method-maximal fuzzy similarity," in Proceedings of the 13th Mini-EURO Conference (Handling Uncertainty in the Analysis of Traffic and Transportation Systems) and the 9th Mtg. EURO Working Group on Transportation (Intermodality, Sustainability and Intelligent Transportation Systems), pp. 716-728, 2001.

[52] J. Niittymäki and E. Turunen, "Traffic signal control on similarity logic reasoning," Fuzzy Sets and Systems, vol. 133, no. 1, pp. 109-131, 2003.

[53] J. H. Lemelson, R. D. Pedersen, and S. R. Pedersen, "Intelligent traffic control and warning system and method," Patent US6317058, B1, 2001.

[54] E. Bingham, Neurofuzzy traffic signal control [M.S. thesis], Helsinki University of Technology, Department of Engineering Physics and Mathematic, Helsinki, Finland, 1998.

[55] D. Teodorovic, P. Lucic, J. Popovic, S. Kikuchi, and B. Stanic, "Intelligent isolated intersection," in Proceedings of the 10th IEEE International Conference on Fuzzy Systems, vol. 1, pp. 276-279, Melbourne, Australia, 2001.

[56] Y. S. Murat and E. Gedizlioglu, "A fuzzy logic multi-phased signal control model for isolated junctions," Transportation Research Part C: Emerging Technologies, vol. 13, no. 1, pp. 19-36, 2005.

[57] M. A. P. Jacques, M. Pursula, J. Niittymäki, and I. Kosonen, "The impact of different approximate reasoning methods on fuzzy signal controllers," in Proceedings of the 13th Mini-EURO Conference (Handling Uncertainty in the Analysis of Traffic and Transportation Systems) and the 9th Mtg. EURO Working Group on Transportation (Intermodality, Sustainability and Intelligent Transportation Systems), pp. 184-192, Bari, June 2002.

[58] R. Zeng, G. Li, and G. Lin, "Adaptive traffic signals control by using fuzzy logic," in Proceedings of the 2nd International Conference on Innovative Computing, Information and Control (ICICIC '07), September 2007.

[59] W. B. Zhang, B. Z. Wu, and W.-J. Liu, "Anti-congestion fuzzy algorithm for traffic control of a class of traffic networks," in Proceedings of the IEEE International Conference on Granular Computing, pp. 124-128, 2007.

[60] X. Cheng and Z. Yang, "Intelligent traffic signal control approach based on fuzzy-genetic algorithm," in Proceedings of the 5th International Conference on Fuzzy Systems and Knowledge Discovery (FSKD '08), vol. 3, pp. 221-225, Shandong, China, October 2008.

[61] X. Chen, D. Li, N. Ma, and C. Shao, "Prediction of user perceptions of signalized intersection level of service based on fuzzy neural networks," Transportation Research Record, vol. 2130, no. 1, pp. 7-15, 2009.

[62] F. G. Labanca, P. S. F. De Sousa Jr., M. V. Asari, and M. A. P. Jacques, "Use of genetic algorithm for fuzzy signal controller design-an exploratory study," 2010.

[63] Y.-J. Gong, J. Zhang, O. Liu, and Y. Li, "A novel fuzzy model for the traffic signal control of modern roundabouts," in Proceedings of the IEEE International Conference on Systems, Man, and
Cybernetics (SMC '11), pp. 1777-1782, Anchorage, Alaska, USA, October 2011.

[64] G. Lu, F. Guan, and D. A. Noyce, "Multimodal accessibility of modern roundabouts: intelligent management system versus common signalization scheme," Journal of the Transportation Research Board, vol. 2183, no. 1, pp. 103-119, 2010.

[65] J. Qiao, N. Yang, and J. Gao, "Two-stage fuzzy logic controller for signalized intersection," IEEE Transactions on Systems, Man, and Cybernetics Part A:Systems and Humans, vol. 41, no. 1, pp. 178-184, 2011. 


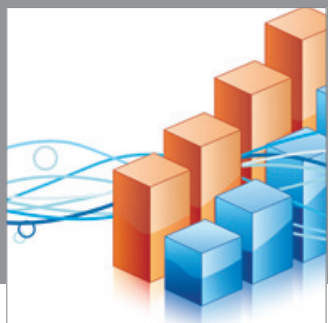

Advances in

Operations Research

mansans

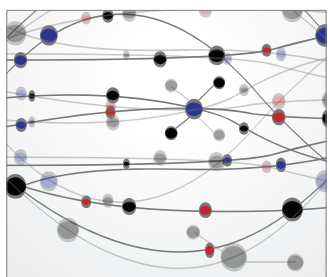

The Scientific World Journal
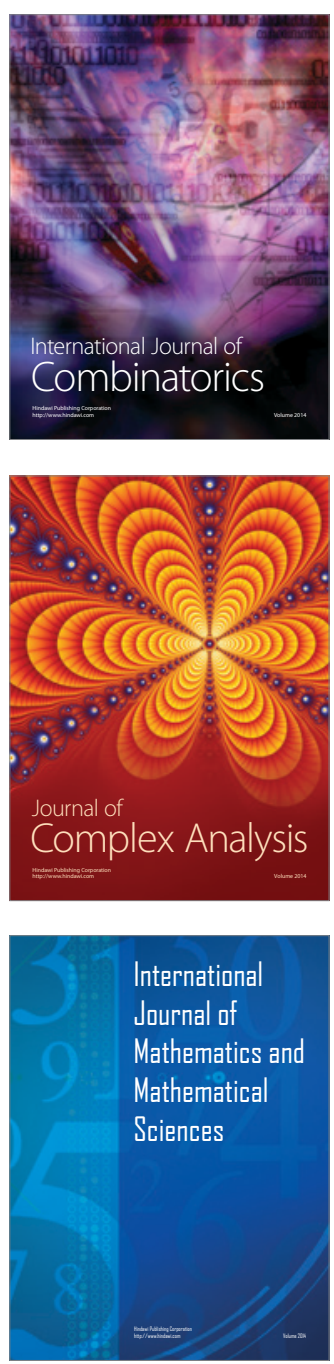
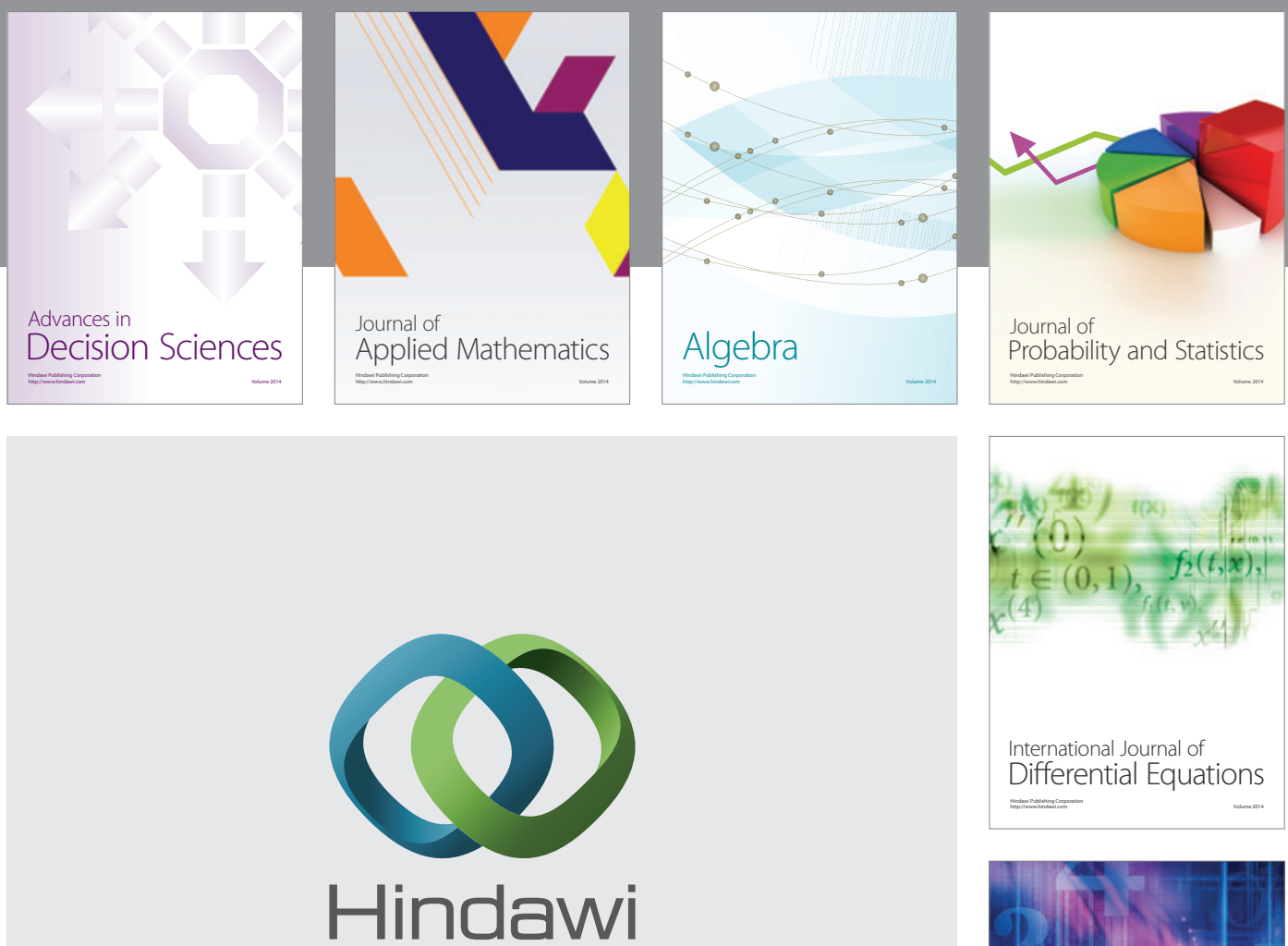

Submit your manuscripts at http://www.hindawi.com
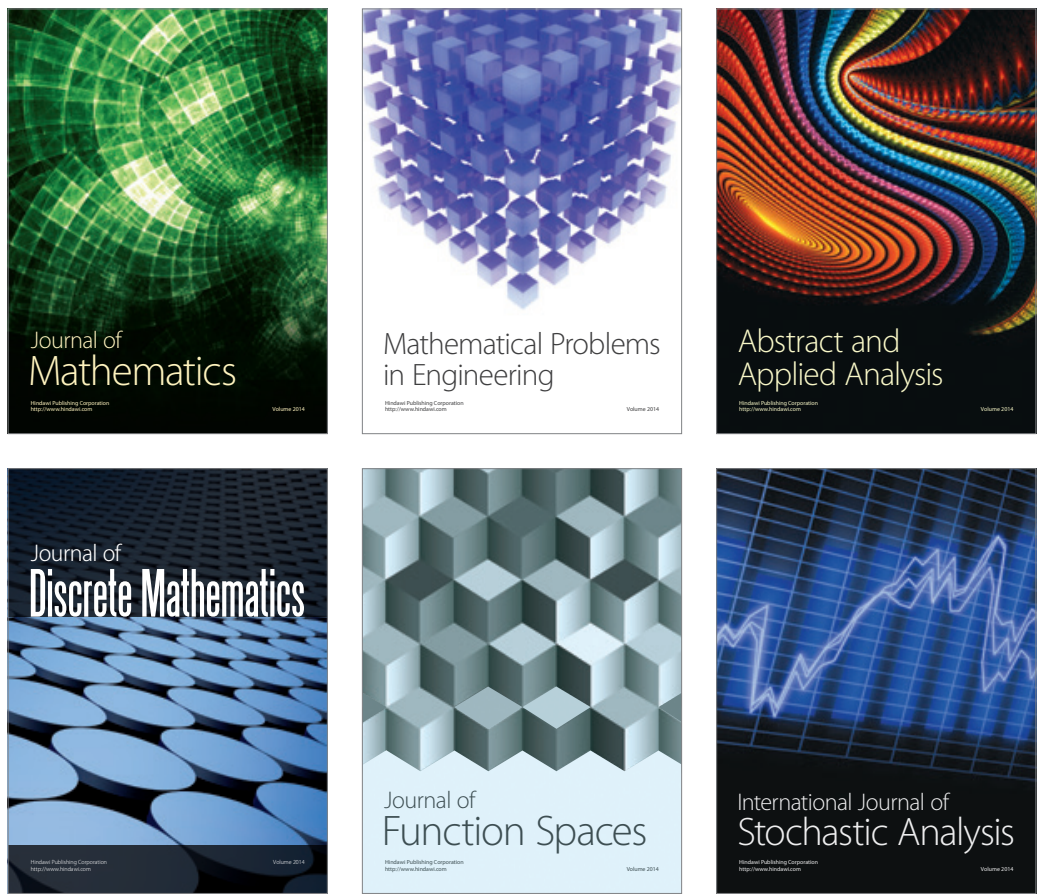

Journal of

Function Spaces

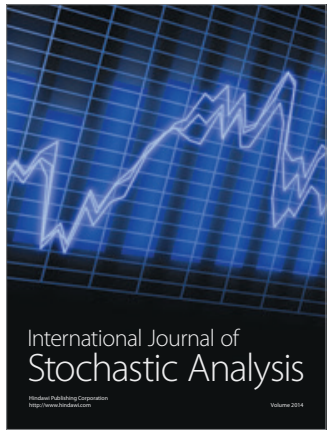

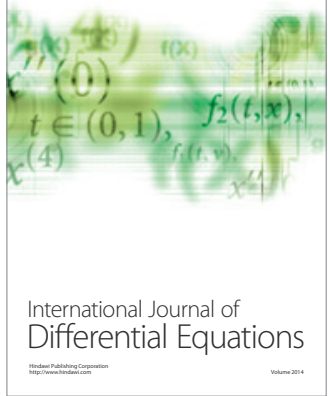
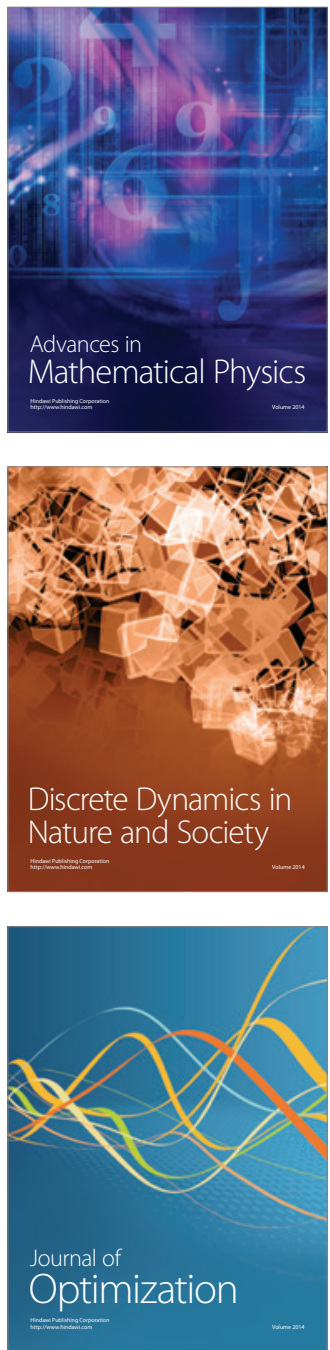